\title{
Safety, efficacy and delivery of isometric resistance training as an adjunct therapy for blood pressure control: a modified Delphi study
}

\author{
Biggie Baffour-Awuah ${ }^{1} \cdot$ Melissa J. Pearson ${ }^{1} \cdot$ Neil A. Smart ${ }^{1} \cdot$ Gudrun Dieberg $^{2}$ \\ Received: 1 July 2021 / Revised: 18 October 2021 / Accepted: 5 November 2021 / Published online: 12 January 2022 \\ (c) The Author(s) 2021. This article is published with open access
}

\begin{abstract}
Uncontrolled hypertension remains the major risk factor for cardiovascular disease. Isometric resistance training (IRT) has been shown to be a useful nonpharmacological therapy for reducing blood pressure (BP); however, some exercise physiologists and other health professionals are uncertain of the efficacy and safety of IRT. Experts' consensus was sought in light of the current variability of IRT use as an adjunct treatment for hypertension. An expert consensus-building analysis (Delphi study) was conducted on items relevant to the safety, efficacy and delivery of IRT. The study consisted of 3 phases: (1) identification of items and expert participants for inclusion; (2) a two-round modified Delphi exercise involving expert panelists to build consensus; and (3) a study team consensus meeting for a final item review. A list of 50 items was generated, and 42 international experts were invited to join the Delphi panel. Thirteen and 10 experts completed Delphi Rounds 1 and 2, respectively, reaching consensus on 26 items in Round 1 and 10 items in Round 2. The study team consensus meeting conducted a final item review and considered the remaining 14 items for the content list. A final list of 43 items regarding IRT reached expert consensus: 7/10 items on safety, 11/11 items on efficacy, 10/12 items on programming, $8 / 10$ items on delivery, and 7/7 on the mechanism of action. This study highlights that while experts reached a consensus that IRT is efficacious as an antihypertensive therapy, some still have safety concerns, and there is also ongoing conjecture regarding optimal delivery.
\end{abstract}

Keywords Blood pressure $\cdot$ Delphi $\cdot$ Isometric resistance training

\section{Introduction}

Chronic disease is the leading cause of death and disability globally, with a disease burden accounting for $71 \%$ (41 million) of all deaths each year. Chronic disease occurs subsequent to genetic, physiological, environmental and behavioral factors and often has long-lasting consequences [1]. The majority of deaths $(85 \%)$ between the ages of 30

Supplementary information The online version contains supplementary material available at https://doi.org/10.1038/s41440021-00839-3.

Biggie Baffour-Awuah

bbaffour@myune.edu.au

1 Clinical Exercise Physiology, School of Science and Technology, Faculty of Science, Agriculture, Business and Law, University of New England, Armidale, NSW 2351, Australia

2 Biomedical Sciences, School of Science and Technology, Faculty of Science, Agriculture, Business and Law, University of New England, Armidale, NSW 2351, Australia and 69 years are premature, with cardiovascular diseases (CVDs) accounting for 15\% ( 18 million) of the total [1,2]. In an attempt to reduce the burden of CVDs, the WHO supports the implementation of cost-effective interventions (both population-wide and individual) for the prevention and control of CVDs [3]. Hypertension remains the major risk factor for CVDs and many other medical conditions, causing sequelae that contribute to many chronic diseases. It is a major cause of premature death, with $\sim 1.13$ billion adults having hypertension worldwide. In two-thirds of affected people, hypertension is uncontrolled [4] and may lead to organ damage (affecting the heart, kidneys, brain, etc.) [5]. A $25 \%$ reduction in the prevalence of hypertension by 2025 (with 2010 as the baseline year) was established as one of the targets in the Global Action Plan for the Prevention and Control of Noncommunicable Diseases (2013-2020), which directly focuses on preventing and controlling CVDs [3]. The prevalence of hypertension increases significantly with age [6] despite efforts to control it. Suitable pharmacological intervention is vital in the management and treatment of hypertension; however, less 
than half of those treated worldwide experience effective blood pressure control [7]. A recent review showed that intensively treating BP lowers the relative risk of major cardiovascular events (26\%) and all-cause mortality (18\%); however, this often involves the use of multiple medications that have unavoidable additional side effects, some of which are secondary to hypotension [8]. This underscores the significance of delivery gaps and calls for alternative/ adjunct antihypertensive therapies.

Population-wide interventions focus on lifestyle modifications; for example, exercise has a significant effect on BP in addition to other health benefits [9]. However, these interventions require long-term commitment for effective results, and poor adherence remains a major drawback [10-12]. Therefore, it is worth considering the cost and time efficiency of exercise interventions to increase compliance, as most patients will not adhere to this lifestyle modification [13]. Both dynamic resistance training (DRT) and aerobic exercise training (AET) are recommended for their antihypertensive effects, even though a study by Schroeder et al. [14] and a recent meta-analysis [15] suggest that combined training may provide more comprehensive CVD benefits than isolated aerobic or resistance training. Nevertheless, the exercise modality of AET is preferred over DRT, which is a recommended supplement, according to exercise guidelines for managing hypertension [16-28]. Participation in and adherence to AET remain low, most likely due to the time and cost $[29,30]$ involved in accessing a gymnasium or equipment (to accommodate orthopedic limitations) and the professional supervision that may be required for some high-risk populations [9].

Numerous randomized controlled trials have demonstrated the antihypertensive benefits of isometric resistance training (IRT) conducted in healthy individuals [31-36] and chronic disease patients [37-40]. Current meta-analyses [41-47] support the status of IRT as an emerging alternative antihypertensive therapy. Isometric resistance training is the execution of a static, sustained muscle contraction against an immovable source of resistance with little or no change in the length of the muscle group(s) involved [9]. Isometric resistance training produces a much lower rate-pressure product (RPP) index than either AET or DRT [48, 49]. The rate-pressure product, defined as the product of systolic blood pressure and heart rate, is used as a measure of myocardial oxygen consumption [50]. Some exercise experts as well as other health care specialists who utilize exercise as a treatment modality remain unconvinced as to the safety of IRT despite the existence of some guidelines that recommend IRT as an adjunct therapy to lower BP [16, 51]. The Canadian guidelines [19], for example, suggest the use of resistance or weight training exercise (such as free weight lifting, fixed weight lifting, or handgrip exercise) for pre-hypertensive or stage 1 hypertensive individuals, as this does not adversely influence BP.
Similarly, a recently updated Exercise \& Sport Science Australia (ESSA) position statement on exercise and hypertension recommends IRT as an adjunct antihypertensive therapy [52]. This is supported by a recent meta-analysis that shows no significant increase in risk when IRT is performed [53]. However, some guidelines do not mention IRT [17, 23, 26, 54, 55] or do not recommend it $[24,25]$ as a result of the perceived acute increase in BP during exercise. Hansen et al. [56], in their consensus statement from the Exercise Prescription in Everyday Practice and Rehabilitative Training (EXPERT) working group for exercise prescription in patients with different combinations of CVD risk factors, identified IRT as an adjunct tool to lower blood pressure [56]. They suggested that the paucity of data warranted further research (level of evidence: $2+$; grade of recommendation: $\mathrm{C}$ ) according to the grading recommendations in evidence-based guidelines [57] for exercise prescription. More importantly, an official document of the American College of Sports Medicine, recently published by Pescatello et al. [58], suggested that there is no conclusive evidence for the antihypertensive benefit of IRT, basing this statement solely on a previous meta-analysis [41]. There are more recent and robust metaanalyses [42, 44] as well as several recent empirical studies $[45,46,53,59,60]$ that demonstrate the safety and effectiveness of IRT in managing hypertension. Similarly, recent work by Fu et al. [61] identified IRT as an effective antihypertensive therapy. These authors performed a network meta-analysis to synthesize direct and indirect evidence from studies that compared multiple interventions to lower BP (120 studies, including 22 with nonpharmacological interventions) [61]. Despite overwhelming evidence from RCTs, systematic reviews and meta-analyses as well as recommendations in international guidelines, there is ongoing conjecture about IRT. In light of this situation, a modified Delphi method was employed to seek expert consensus building with the aim of identifying the relevant issues worth considering for the safety, efficacy, and delivery of IRT as an adjunct therapy in the management of hypertension.

\section{Methods}

The Delphi technique is commonly used in health care research and seeks opinions from a group of experts to assess the level of agreement and resolve disagreement on an important issue $[62,63]$. In this study, a modified Delphi technique was used to build consensus [64] on a set of items generated through an extensive literature review. This project was approved by the Human Research Ethics Committee of the University of New England (Approval No. HE20-180). 
Steered by the study team's (BB, MP, GD and NS) evaluation of the literature on IRT research and current guidelines for the application of IRT, consensus building was conducted in three phases:

1. Identification of items regarding the safety, efficacy and delivery of IRT and expert participants for inclusion (August-October 2020);

2. A 2-round modified Delphi study conducted to build consensus (October 2020-January 2021); and

3. A consensus group meeting among the study team to finalize items (February 2021).

\section{Phase 1: Identification of items and expert participants for inclusion}

After a careful review of the available literature investigating IRT and with reference to systematic reviews and meta-analyses [9, 41-44, 46, 59-61, 65-69], the study team reached an agreement on the inclusion/exclusion of potential items in relation to the antihypertensive effects of IRT. A set of statements was developed as items for the current study. These items were categorized under five subheadings: safety, efficacy, programming, delivery and mechanism of action of IRT. Some items negating previous statements were included to validate participants' responses. A first draft of these items served as a pilot test for comments and suggestions before the questionnaire was finalized using the online survey software Qualtrics (Qualtrics, Provo, UT, USA).

Once the questionnaire was finalized, the experts were selected; an "expert" was defined as an individual involved in IRT research and/or the use of exercise intervention as an adjunct treatment method. The panelists were identified and selected based on their area of expertize and specified inclusion criteria (see below) [70]; these individuals included (1) exercise professionals working in a clinical or academic setting and (2) health care professionals with experience in the use of exercise as a treatment modality or experience in developing exercise guidelines.

Thus, the sampling technique was purposive and based on selected criteria [69]. Since IRT is an emerging area, the number of potential expert panelists worldwide is relatively low; therefore, panelists were recruited with no geographic limitations. Potential expert panelists were identified at tertiary education institutions, research institutes, and health care providers through IRT networks, internet searches and authorship of relevant publications. Their contact addresses (email) were obtained from their staff profiles on their organizations' websites or from published studies.

The inclusion criteria for potential expert panelists were as follows:
1. Academics with at least one peer reviewed publication in isometric exercise research.

2. Exercise or healthcare professionals who

a. are specialists using exercise in the management of chronic diseases (especially cardiovascular diseases), and

b. have a relevant postgraduate qualification or at least 3 years' experience in an exercise and sports or musculoskeletal setting.

3. Currently employed as an academic or professional in clinical practice.

4. At least 18 years old and proficient in English.

Potential expert panelists were included if they met criteria 1 and/or 2, plus mandatory criteria 3 and 4 . Potential panelists were excluded if they were academics (criterion 1) with no IRT research publications.

\section{Phase 2: Modified Delphi study to build a consensus}

The second phase of the study involved the distribution of invitation emails to the identified experts for inclusion as panelists. Qualtrics was used to communicate with experts/ panelists, obtain their consent to participate, and administer the questionnaires [71]. Invited experts who consented to participate were given access to the survey to review each generated item and rate their agreement with it. Expert panelists were asked to complete two consecutive rounds of the Delphi process over 10 weeks and remained anonymous to the other panel members. During this period, a reminder email was sent a week before the end of each round, addressed only to panelists who had not yet responded. Panelists' feedback and suggestions in Round 1 were incorporated into the Round 2 survey.

\section{Delphi round 1}

Potential experts were invited via an email with an embedded "Information Sheet for Participants", which contained detailed information about the study and a link to "Agree" or "Disagree" to take part in the study. Upon acceptance, experts were asked to consent to participation. Specifically, they were informed that accepting the invitation to participate in the study would constitute implied consent. It was only at this point that the panelists were given access to the online survey to evaluate the set of items presented. This was described as Round 1.

In Round 1, panelists were asked to evaluate items in relation to the safety, efficacy, programming, delivery and mechanism of action of IRT, considering the benefits of IRT compared to other exercise training programs used as 
nonpharmacological therapy. Items were presented in a randomized order, and panelists graded their opinions of each item using a 5-point Likert scale (strongly disagree (1), disagree (2), do not know (3), agree (4) and strongly agree (5)) to indicate their level of agreement. In addition, panelists were encouraged to provide comments to explain their responses, suggest modifications to any of the items or add further items through free-response text feedback.

Responses from Round 1 were analyzed quantitatively using descriptive statistics for the central tendency (median) and distribution width (interquartile range) to present the collective judgments of the panelists. This information, together with panelists' deidentified comments, suggested modifications and/or additional items, was provided to the panelists as feedback. The panelists' comments and suggestions informed Round 2, and the panelists were encouraged to reconsider their opinions on any items that had not reached consensus.

\section{Delphi round 2}

Panelists who responded to the Round 1 questionnaire were invited to complete Round 2 of the Delphi exercise. For their information, these panelists were sent an email containing a summary of the Round 1 analysis and feedback; they also received the Qualtrics link to the Round 2 questionnaire containing the set of items that did not reach consensus in Round 1. The Round 1 analysis summary comprised the aggregated percentage of agreement for each item along with deidentified suggested modifications and feedback comments from Round 1 and the modified versions of statements where necessary. Each Round 2 statement was either the original or a modified version based on the Round 1 feedback from panelists. Each modified version consisted of the original statement altered by removing, replacing, and/or rephrasing some of the text (indicated by bolding the rephrased or replaced words) or by adding explanatory notes that elaborated further to make the statement clearer and more specific. In this round, items were grouped by their subheadings.

At the end of Round 2, the analysis and feedback processes were repeated with the a priori consensus criteria. Thus, the process yielded two sets of items: one set retained by consensus (experts consistently agreed or consistently disagreed with each item) and another set without a consensus.

\section{Phase 3: Study team consensus meeting (final item review)}

Following Round 2 of the Delphi exercise, all results were discussed by the study team in a final item review. It is common practice to hold a consensus meeting, stakeholder meeting or final item review as the final step of a Delphi study, especially in health care research [62, 72-79]. A similar Delphi approach (two Delphi rounds plus a consensus meeting group), with panel members included in consensus meeting groups, has been reported by other studies [74-77]. The study team members who participated in the final item review are also experts in the area of IRT; all of them have practical experience and publications.

All items on which the expert panelists reached a consensus in both rounds of Delphi exercise were accepted, and items on which the panel did not reach a consensus were discussed in the final item review. Decisions to either accept or reject these remaining items were based on expert panelists' agreement ratings ( $\geq 50 \%$ agreement and $\leq 30 \%$ disagreement), consultation of existing guidelines and systematic reviews with meta-analyses, and the team members' professional experience [64]. The aim was to finalize the content of the list of statements relating to the safety, efficacy, programming, delivery and mechanism of action of IRT.

\section{Statistical analyses}

Descriptive statistics were used to summarize participants' demographic characteristics (including age, gender, profession, level of education, and years of experience) and panelists' responses to each statement in the two rounds of the Delphi process. We defined a priori consensus as $\geq 75 \%$ agreement (5-point Likert Scale) with a median $\geq 4$ and interquartile range $(\mathrm{IQR})<2$ [80]. For the criterion of $\geq 75 \%$ agreement or disagreement, the 5 levels of the Likert scale were consolidated into 3 categories: "strongly agree/agree", "strongly disagree/disagree" and "do not know". Analyses were conducted using IBM SPSS Statistics version 25 for Windows [81].

\section{Results}

This modified Delphi study aimed to investigate expert consensus on the safety, efficacy and delivery of IRT as an adjunct therapy for the management of hypertension.

\section{Phase 1: Identification of items and expert participants for inclusion}

A total of 50 items were generated in relation to the safety, efficacy and delivery of IRT. Items were categorized into five subheadings: safety (10 items), efficacy (11 items), programming (12 items), delivery (10 items) and mechanism of action (7 items) (Supplementary Table 1). Forty-two experts were identified based on our predefined inclusion criteria for "expert" panelists; of these eligible experts, 13 
Fig. 1 Flow diagram of the items and expert panellists in three phases of the study

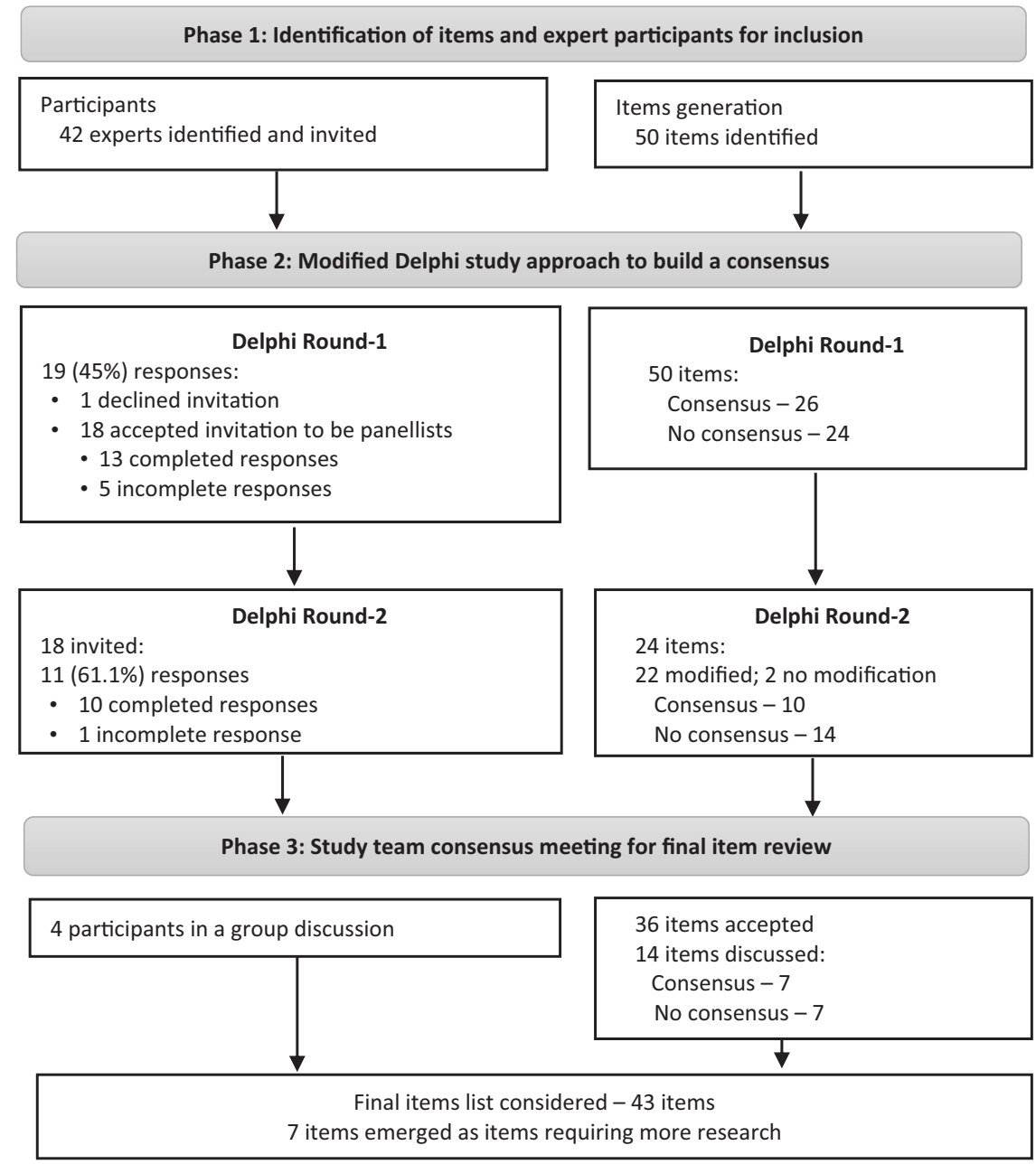

and 10 expert panelists fully completed Round 1 and Round 2 , respectively. Figure 1 shows a flow diagram of items and panelists through the three phases of the study.

\section{Phase 2: Modified Delphi study to build a consensus}

An invitation to participate in the study was emailed to the 42 potential experts. When the invitation emails were sent, there were no bounced emails or duplicate addresses. However, one address bounced when the reminder email sent to those who did not respond within the threeweek period after the first invitation email was sent. There were 19 responses; however, one expert declined to participate. Thus, 18 (43\%) experts who met the inclusion criteria consented to participate in the study.

\section{Delphi round 1}

In Round 1 of the Delphi survey, there were 13 complete and 5 incomplete/partial sets of responses to the questionnaire. The 5 participants with incomplete responses were excluded from the analyses as missing data because they had completed less than $20 \%$ of the questionnaire. The remaining 13 panelists, who were included in the analyses, comprised 8 males and 5 females aged between 25 and 64 years with academic/research expertize (9) or clinical expertize (1) and three experts who had both academic and clinical expertize. The demographic profiles of the experts are detailed in Table 1. At the end of Round 1, the panel reached a consensus on $26(52 \%)$ items. These items were not included in Round 2. The 24 items on which the panel did not reach a consensus included items related to safety ( 8 out of 10 items), efficacy ( 1 out of 11 items), programming (5 out of 12 items), delivery (6 out of 10 items) and the mechanism of action (4 out of 7 items).

Overall, 31 items were modified ( 9 items that reached consensus and 22 items to be rerated in Round 2) following the analysis of Round 1 feedback. Ten of the modified versions had explanatory notes added to either the original or a modified statement. The outcome responses for Round 1 are presented by subheading (safety, efficacy, delivery, programming and mechanism of action of IRT) in Supplementary Table 1. 
Table 1 Demographic characteristics of Delphi participants

\begin{tabular}{|c|c|c|}
\hline Characteristics & Panelists & $n(\%)=13$ \\
\hline \multirow[t]{2}{*}{ Gender } & Male & $8(61.5)$ \\
\hline & Female & $5(38.5)$ \\
\hline \multirow[t]{2}{*}{ Age (years) } & $25-54$ & $9(69.2)$ \\
\hline & $55-64$ & $4(30.8)$ \\
\hline \multirow[t]{3}{*}{ Education } & $\begin{array}{l}\text { Second degree (Master)/ } \\
\text { specialization }\end{array}$ & $1(7.7)$ \\
\hline & $\begin{array}{l}\text { Third degree }(\mathrm{PhD}) / \text { sub- } \\
\text { specialty }\end{array}$ & 11 (84.6) \\
\hline & $\begin{array}{l}\text { Other (specification) - MD } \\
\text { and } \mathrm{PhD}\end{array}$ & $1(7.7)$ \\
\hline \multirow{7}{*}{$\begin{array}{l}\text { Profession (by } \\
\text { specification) }\end{array}$} & Clinical exercise physiologist & $7(53.8)$ \\
\hline & $\begin{array}{l}\text { Academic - Anatomy, } \\
\text { Physiology, Pathophysiology }\end{array}$ & $1(7.7)$ \\
\hline & Exercise \& sport physician & $1(7.7)$ \\
\hline & Exercise scientist & $1(7.7)$ \\
\hline & Physical education & $1(7.7)$ \\
\hline & $\begin{array}{l}\text { Physician- GP specializing in } \\
\text { sports and exercise medicine }\end{array}$ & $1(7.7)$ \\
\hline & Professor of Kinesiology & $1(7.7)$ \\
\hline \multirow{5}{*}{$\begin{array}{l}\text { Years of professional } \\
\text { experience }\end{array}$} & $<5$ & $1(7.7)$ \\
\hline & $5-10$ & $6(46.2)$ \\
\hline & $11-15$ & $2(15.4)$ \\
\hline & $16-20$ & $1(7.7)$ \\
\hline & $>20$ & $3(23.1)$ \\
\hline \multirow{6}{*}{$\begin{array}{l}\text { Country of } \\
\text { primary work }\end{array}$} & Australia & $2(15.4)$ \\
\hline & Brazil & $4(30.8)$ \\
\hline & Canada & $2(15.4)$ \\
\hline & Chile & $1(7.7)$ \\
\hline & UK & $2(15.4)$ \\
\hline & USA & $2(15.4)$ \\
\hline \multirow[t]{4}{*}{ Area of primary work } & Academic & $8(61.5)$ \\
\hline & Hospital/clinic & $1(7.7)$ \\
\hline & Sports and exercise facility & $1(7.7)$ \\
\hline & Academic and clinical & $3(23.1)$ \\
\hline \multirow{3}{*}{$\begin{array}{l}\text { Primary area of } \\
\text { expertize for IRT }\end{array}$} & Academic/research expertize & $9(69.2)$ \\
\hline & Clinical expertize & $1(7.7)$ \\
\hline & Both & $3(23.1)$ \\
\hline \multirow{11}{*}{$\begin{array}{l}\text { For academic/ } \\
\text { research experts }\end{array}$} & H-index & \\
\hline & $<10$ & $3(23.1)$ \\
\hline & $10-20$ & $3(23.1)$ \\
\hline & $21-30$ & $5(38.5)$ \\
\hline & $31-39$ & 0 \\
\hline & $>40$ & $1(7.7)$ \\
\hline & Publications in total & \\
\hline & $<20$ & $3(23.1)$ \\
\hline & $21-50$ & $2(15.4)$ \\
\hline & $51-100$ & $3(23.1)$ \\
\hline & $>100$ & $4(30.8)$ \\
\hline
\end{tabular}

Table 1 (continued)

\begin{tabular}{lll}
\hline Characteristics & Panelists & $n(\%)=13$ \\
\hline & Publications in IRT research & \\
1 & 2 & $3(7.7)$ \\
For clinical expertize & Years since qualification & $1(7.7)$ \\
& $<5$ & $7(53.8)$ \\
& $5-10$ & $2(15.4)$ \\
& $>20$ & $1(7.7)$ \\
& Current rank & $1(7.7)$ \\
& $\begin{array}{l}\text { Senior practitioner } \\
\text { Clinical specialist/extended }\end{array}$ & $1(7.7)$ \\
& scope practitioner/advanced & \\
& clinical practice & \\
\hline
\end{tabular}

\section{Delphi round 2}

For Round 2, invitations were sent to 18 panelists, 11 (61\%) of whom responded. There was one incomplete response, which was excluded as missing data; thus, 10 panelists' responses were included in the analysis. In Round 2, the remaining 24 items that did not reach consensus in Round 1 were rerated, with 22 items modified based on suggestions from panelists. At the end of Round 2, an additional 10 $(41 \%)$ items reached consensus among the panelists, while 14 items failed to reach consensus. The panelists' responses for Round 2 are summarized in Supplementary Table 1, which includes their agreement in each round for consensus and inclusion in the content list.

\section{Phase 3: Study team consensus meeting (final item review)}

In a final item review, the study team accepted all 36 items that reached consensus in Rounds 1 and 2 of the Delphi study. The remaining 14 items regarding safety (4), efficacy (1), programming (3), delivery (4) and mechanism of action (2) that did not reach consensus at the end of Round 2 were discussed at length. The team accepted 7 of the 14 items and deemed another 7 items inconclusive (i.e., "not accepted"). These were excluded because more research is needed to confirm each item. The team's decision on these items is documented in Supplementary Table 2.

By the end of the Delphi study, 43 items had reached expert consensus (including two items that negated previous statements) and were accepted for IRT - 7 out of 10 items on safety, 11 out of 11 items on efficacy, 10 out of 12 items on programming, 8 out of 10 items on delivery, and 7 out of 7 items on the mechanism of action. Three items related to safety (2 
Table 2 List of accepted items

No Item description

\section{Safety}

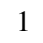

2

3

4

5

6

Efficacy

1

2

3

4

5

6

7

8

9

10

11

Programming

1

2

3

4

5

6

7

8

9

10
In general, leg IRT employed at an appropriate training intensity (e.g., 20\% MVC) causes blood pressure responses of $>30 \mathrm{mmHg}$ in SBP or $20 \mathrm{mmHg}$ in DBP.

IRT at an appropriate training intensity (e.g., 30\% MVC for handgrip or 20\% MVC for leg) causes smaller increases in rate pressure product (SBP x HR) compared to moderate intensity aerobic exercise.

An appropriate IRT program is safe for people with pre-hypertension.

An appropriate IRT program is safe for people with stage 1 hypertension.

In general, an appropriate IRT program is safe for people with cardiovascular diseases.

An appropriate IRT program is safe for people with peripheral artery disease.

A program of IRT of 8 weeks or longer elicits statistically significant reductions in SBP in healthy individuals.

A program of IRT of 8 weeks or longer elicits statistically significant reductions in DBP in healthy individuals.

A program of IRT of 8 weeks or longer elicits statistically significant reductions in SBP in cardiovascular disease patients.

A program of IRT of 8 weeks or longer elicits statistically significant reductions in DBP in cardiovascular disease risk patients.

A program of IRT of 8 weeks or longer elicits clinically meaningful reductions (i.e., $\geq 2 \mathrm{mmHg}$ reduction) in SBP in healthy individuals.

A program of IRT of 8 weeks or longer elicits clinically meaningful reductions (i.e., $\geq 2 \mathrm{mmHg}$ reduction) in DBP in healthy individuals.

A program of IRT of 8 weeks or longer elicits clinically meaningful reductions (i.e., $\geq 2 \mathrm{mmHg}$ reduction) in SBP in cardiovascular disease patients.

A program of IRT of 8 weeks or longer elicits clinically meaningful reductions (i.e., $\geq 2 \mathrm{mmHg}$ reduction) in DBP in cardiovascular disease patients

A program of IRT of 8 weeks or longer elicits SBP and DBP reductions of similar size to those observed with taking one anti-hypertensive medication.

A program of IRT of 8 weeks or longer elicits SBP and DBP reductions that are likely to reduce the risk of a serious event related to poor blood pressure control such as stroke and myocardial infarction.

An appropriate IRT program may potentially be beneficial for people with heart disease as it elicits an ischaemic pre-conditioning response.

A typical handgrip IRT program is $4 \times 2$ min effort at $30 \%$ MVC with $1-3$ min rest periods in between efforts.

A typical leg IRT program is $4 \times 2$ min effort at $20 \%$ MVC with 1-3 min rest periods in between efforts.

A typical IRT protocol performed at a minimum frequency of 3 sessions per week for 8 weeks or longer is enough to obtain a clinically meaningful anti-hypertensive response.

Prior to IRT programming an individual should be pre-screened including appropriate risk assessment by an appropriate health professional.

Ideally, MVC should be measured before every IRT session and training intensity adjusted accordingly to ensure relative effort remains constant.

IRT can be used as an alternative form of exercise to lower blood pressure in people with hypertension who are unable to perform other types of exercise (aerobic or dynamic resistance).

IRT is relatively simple to perform compared to some other forms of exercise.

The handgrip IRT exercise device is portable and simple to transport.

Besides walking an IRT program is relatively inexpensive compared to some other forms of exercise.

An IRT program takes less time to perform and to elicit anti-hypertensive benefits than other types of exercise. 
Table 2 (continued)

\begin{tabular}{|c|c|}
\hline No & Item description \\
\hline \multicolumn{2}{|c|}{ Delivery } \\
\hline 1 & $\begin{array}{l}\text { Handgrip IRT is simple to deliver as one can measure MVC and then prescribe IRT at } 30 \% \mathrm{MVC} \text { and } \\
\text { this may also reduce barriers to dynamic exercise training. }\end{array}$ \\
\hline 2 & Handgrip IRT below 5\% MVC is unlikely to elicit anti-hypertensive benefits. \\
\hline 3 & $\begin{array}{l}\text { Leg IRT is more difficult to prescribe as opposed to handgrip IRT as sophisticated laboratory/gym } \\
\text { equipment is required to determine MVC for leg IRT. }\end{array}$ \\
\hline 4 & $\begin{array}{l}\text { Handgrip IRT performed at MVC above } 30 \% \text { is sub-optimal as it increases the risk of exaggerated } \\
\text { blood pressure responses and reduces the ability of people to complete their handgrip program. }\end{array}$ \\
\hline 5 & $\begin{array}{l}\text { Handgrip IRT employed at an appropriate training intensity can be prescribed by a qualified exercise } \\
\text { specialist for home-based training with little or no supervision - using the appropriate risk assessment } \\
\text { prior to training. }\end{array}$ \\
\hline 6 & $\begin{array}{l}\text { Leg IRT employed at an exact training intensity of } 20 \% \text { MVC can be prescribed by a qualified } \\
\text { exercise specialist for home-based training with little or no supervision. }\end{array}$ \\
\hline 7 & $\begin{array}{l}\text { Prescription of handgrip IRT is preferred to leg IRT for home-based delivery as the former is } \\
\text { inexpensive and easier to use compared to the later which requires sophisticated laboratory/gym } \\
\text { equipment to determine precise MVC. }\end{array}$ \\
\hline \multicolumn{2}{|c|}{ Mechanism of action } \\
\hline 1 & $\begin{array}{l}\text { A possible mechanism for IRT to work is via repeated exposure to blood vessel occlusion that causes } \\
\text { shear stress on the arterial wall with a resultant increase in nitric oxide release triggering vasodilation. }\end{array}$ \\
\hline 2 & $\begin{array}{l}\text { Repeated exposure of IRT may cause permanent changes in blood vessels (e.g., diameter) with time. } \\
\text { Longer term (i.e., } \geq 6 \text { months) might lead to more consistent blood pressure adaptations. }\end{array}$ \\
\hline 3 & IRT generates reactive hyperaemia which is facilitated by vasodilation. \\
\hline 4 & $\begin{array}{l}\text { Repeated exposure to IRT increases baroreflex sensitivity which may improve cardiac autonomic } \\
\text { modulation. }\end{array}$ \\
\hline 5 & $\begin{array}{l}\text { Depending on the length of the protocol, the anti-hypertensive effects of IRT are reversed within } \\
2-5 \text { weeks detraining. }\end{array}$ \\
\hline 6 & The anti-hypertensive effects of IRT are transient if the individual discontinues the training. \\
\hline 7 & $\begin{array}{l}\text { The anti-hypertensive effects of IRT are semi-permanent (e.g., lasting up to } 4 \text { weeks) if training is } \\
\text { discontinued. }\end{array}$ \\
\hline
\end{tabular}

Note: Two items that negated a previous statement have been excluded from accepted items

items for handgrip IRT and one item for all IRT irrespective of leg or handgrip training), 2 items for delivery of leg IRT, and 2 items for programming of handgrip IRT were excluded. Table 2 shows the final list of accepted items, excluding two items (one each for safety and delivery) that negated other statements.

\section{Discussion}

This study examines pertinent issues regarding the safety, efficacy, and delivery of IRT. This is the first formal consensus-building exercise based upon items generated from evidence-based literature on the antihypertensive effects of IRT, and this study involved experts with both academic and clinical experience in this field of research. IRT is an emerging antihypertensive therapy; given this status, concerns may remain around matters such as safety, efficacy and delivery. We therefore compiled a set of 50 items considered important in relation to the safety, efficacy, programming, delivery and mechanism of action of IRT. This modified Delphi study called on the expertize and reflection of the panelists and had them rate their agreement on the use and antihypertensive effect of IRT.

Round 1 feedback from panelists informed modifications to some items for rerating in Round 2 as well as some items that had already reached consensus in Round 1. These modifications were minor and made the statements clearer and more specific. In two items, the original statements were negated by adding "does not". The main purpose of this reversal was to substantiate the validity of panelists' responses with reference to the original statements (we expected the opposites of their original responses). After Round 1 and Round 2, a total of 36 items (out of 50) achieved $\geq 75 \%$ consensus among the expert panelists. The remaining 14 items, with $<75 \%$ consensus, were discussed by the study team for either inclusion ( 7 items) or exclusion (7 items) in the final item review, considering the comments from the panelists as well as evidence-based research and guidelines.

The present Delphi study identified a set of 43 out of 50 statements that support the use of IRT as an adjunct therapy for the control of blood pressure in both healthy 
people and those living with hypertension. All items related to the efficacy and mechanism of action of IRT reached expert consensus; only a few items related to safety (3), delivery (2) and programming (2) failed to reach consensus. Despite the previous concerns addressed by Hansen et al. [56] and Pescatello et al. [58] regarding the use of IRT in clinical practice, this study showed consensus (in consultation with evidencebased literature) on the benefits of IRT as an adjunct treatment for hypertension. This Delphi study is in agreement with the findings of Wiles et al. [82], Carlson et al. [83] and Smart et al. $[9,44]$ regarding the safety of IRT and the findings of Herrod et al. [35], Carlson et al. [84] and Wiles et al. [85] on its efficacy. The results are also supported by LopezValenciano et al. [43] and Punia et al. [86] concerning the potential use of IRT as an adjunct to lowering BP. Likewise, larger and more robust meta-analyses [42, 44] and current empirical studies [45, 46, 53, 59-61] demonstrate the safety and effectiveness of IRT in preventing hypertension. In addition, the findings show that the set of items is comprehensive, as the panelists suggested no additional items. Even though some comments and feedback were received from panelists, this was to justify their response and to indicate areas that needed more research. The remaining 7 items were excluded from the content, representing emerging areas for future research. These 7 items included 3 items related to safety, 2 items related to delivery, and 2 items related to programming (see Supplementary Table 2). Regarding the safety of IRT, 3 items relating to increases in BP and HR did not reach consensus. It is important to note that blood pressure usually increases with exercise as a result of the increased oxygen demand of working muscles; mechanistically, this rise in blood pressure occurs via increased sympathetic tone, which results in increased cardiac output [87]. During exercise, it is normal for some individuals to have an exaggerated blood pressure increase, which usually returns to baseline levels after exercise irrespective of the type of exercise [88]. This phenomenon is known as a hypertensive response to exercise (HRE), and there is no consensus on the exact extent of HRE in IRT [87-90]. O'Driscoll et al. [91] recently showed that BP increased significantly from baseline at the onset of isometric exercise and remained elevated during the exercise session; afterward, recovery resulted in a significant reduction in BP, even below baseline. Although HRE is considered an irregular response, the variable increase differs among individuals in a manner that suggests the partial influence of genetic variation [92-95]. This characterizes HRE as a physiological phenomenon affected by the interaction of both central and reflex neural control mechanisms of the cardiovascular system during exercise [88] as well as the individual's baseline characteristics [96]. Nonetheless, sympathetic nervous system stimulation and the reninangiotensin-aldosterone system have been associated with increases in blood pressure and heart rate during exercise
$[87,88,90]$. Likewise, impaired endothelial vasodilation may contribute to HRE [97, 98]. The majority of work regarding the effect of IRT on blood pressure has focused on the acute and chronic postexercise effects and not on the blood pressure response during exercise. Wiles et al. [82] ascertained the safety of IRT in stage 1 hypertensive patients by investigating the hemodynamic response during isometric wall squat exercise and isometric wall squat training sessions. These authors found that blood pressure and heart rate during isometric exercise were considerably lower than the thresholds recommended by the American College of Sports Medicine (ACSM) guidelines for exercise test termination [99]. Moreover, their highest recorded rate-pressure product $(20,681 \pm$ $3911 \mathrm{mmHg} \times \mathrm{bpm})$ was much less than that reported $(27,729 \pm 5018 \mathrm{mmHg} \times \mathrm{bpm})$ in high-risk patients referred for exercise stress testing (using the Bruce protocol on a treadmill) for ischemic heart disease evaluation [100]. To date, no study has specifically investigated blood pressure responses during IRT compared with other types of exercise (especially aerobic exercise training or dynamic resistance training) in both healthy individuals and those with chronic diseases. However, Seidel et al. [101] have recently reported the differential impacts of AET and IRT on blood pressure variability and central aortic blood pressure. The parameters measured in that study addressed the cumulative effects of exercise after the end of training but not during training. Therefore, further studies are needed to quantify the hemodynamic responses that occur during IRT.

Regarding the delivery and programming of IRT, the four items excluded from the content were all related to leg IRT. The reason why consensus was elusive is likely because more studies involved handgrip IRT than leg IRT. Typically, for targeted leg IRT, a leg extension dynamometer is required; this is usually gymnasium/laboratory equipment used to determine the intensity of maximal voluntary contraction. However, there are other forms of leg IRT that have had similar beneficial effects when performed by normotensive [85, 91], prehypertensive [102] and stage 1 hypertensive patients $[82,103]$ in the context of wall squat exercises. These require a specific degree of knee joint flexion, which can be determined by using a simple tool-a modified clinical goniometer secured at the knee using four 25-mm-wide elastic Velcro leg straps [82]. Similarly, in home-based exercise training, an alternative device was used; this device, the "Bend and Squat" (an improvised tool made in house), aligns a participant's feet and back into the correct position for a given knee joint angle during wall squats [85]. There is still more work to be done in order to quantify the individual's perceived difficulty ratings and adherence to leg IRT for home-based training compared to handgrip IRT and/or other modes of exercise to confirm any apprehensions. Recent work by Lea et al. [104] showed that the rating of perceived exertion assessed across consecutive 
workloads and time points provides a valid and reliable measure of IRT intensity and physiological exertion.

\section{Study highlights and the way forward}

The adoption of IRT as an adjunct therapy remains underutilized in clinical practice and is omitted from some guidelines on hypertension management. The consensus achieved in the current study highlights the safety, efficacy and delivery of IRT, as these are vital for translation into clinical practice. In addition, statements regarding the programming and mechanism of action of IRT reached consensus. There is substantial evidence to support the benefits of IRT in blood pressure control; however, large-scale clinical trials are warranted to foster adoption.

Future research should focus on the following:

1. Real-time hemodynamic studies of blood pressure during IRT compared with other types of exercise (especially aerobic or dynamic resistance training) in healthy participants and people with chronic diseases to quantify the effects during training;

2. Rating individuals' perceptions of the difficulty of leg IRT and adherence to their regimens for home-based training compared to handgrip IRT and/or other modes of exercise to quantify any apprehension in relation to delivery and adherence; and

3. Comparing the effect of leg and handgrip IRT to quantify blood pressure and hemodynamic responses.

\section{Strengths and limitations}

This study has a number of strengths. The literature search for item generation included systematic reviews, from which individual studies were further scrutinized for the effect of IRT on blood pressure response parameters. A modified Delphi technique for consensus building preserved the anonymity of panelists, allowing them to express their opinions freely without any restrictions. This reduced the influence of dominant personalities and/or panel experts' status on the results. It also allowed panel members to make suggestions and provide comments on the potential modification or addition of items. More importantly, this technique is inexpensive and flexible, allowing experts to contribute irrespective of their geographical location without needing to make physical contact. There was diversity in experts' professional backgrounds in relation to exercise and sport science, spanning from academic to clinical practice, with all panelists having at least a graduate degree and years of experience. The majority of the panelists with academic/research expertize had 5 or more publications in IRT research, while those with clinical expertize were ranked as senior practitioners or were in advanced clinical practice and had more than 5 years of experience. However, this study is not free of limitations. The overall response rate in Round 1 (19 out of 42 invited experts-45\%) was low, with 13 out of 19 participants submitting complete responses. This further reduced in Round 2, with 11 out of 18 invited experts responding and 10 submitting complete responses, thus limiting the number of experts involved in making the decisions. The reasons for low respondent rates cannot be explained but could be related to COVID-19 and may include time management issues. The Qualtrics survey could have been set up with a longer active response period to allow more time for completion. This could potentially have compensated for data lost due to incomplete responses.

\section{Conclusion}

This study undertook a modified Delphi process to reach an expert consensus on the safety, efficacy and delivery of IRT as an adjunct therapy in the management of hypertension. Experts reached consensus on the efficacy and mechanism of action of IRT. Some concerns remain in the area of IRT safety and, to a minor extent, in optimal programming and delivery of leg IRT. Future research in these areas is needed to allay concerns and to fully translate IRT into clinical practice.

Acknowledgements We would like to acknowledge all the panelists who participated in this Delphi study for their immense contributions to the development of this paper. These panelists include the following: Professor Claudio Gil Araujo (Gama Filho University, Brazil). Dr. Debra J. Carlson (Central Queensland University, Australia). Dr. Cassandra Stiller-Moldovan (University of Western Ontario, Canada). Assistant Professor Alexis Espinoza-Salinas (Universidad Santo Tomás, Chile). Professor Breno Quintella Farah (Federal Rural University of Pernambuco, Brazil). Dr. Karla Goessler (University of São Paulo, Brazil). Associate Professor Reuben Howden (University of North Carolina at Charlotte, U.S.A.). Ms. Jodie Dianne Inder (Empower Exercise Physiology and Nutrition, Australia). Professor George A. Kelley (Virginia University, U.S.A.). Professor Cheri L. McGowan (University of Windsor, Canada). Professor Philip J. Millar (University of Guelph, Canada). Dr. Rafael Reis Olher (Catholic University of Brasília, Brazil). Associate Professor Bethan E. Phillips (University of Nottingham, UK). Professor Raphael Mendes Ritti-Dias (University of Nove de Julho, Brazil). Professor Ian L. Swaine (University of Greenwich, UK).

Funding BBA is the recipient of a University of New England International Postgraduate Research Award (UNE IPRA) scholarship to support her PhD research. This study was partially funded by the UNE School of Science and Technology Higher Degree Research allocation.

\section{Compliance with ethical standards}

Conflict of interest The authors declare no competing interests. 
Publisher's note Springer Nature remains neutral with regard to jurisdictional claims in published maps and institutional affiliations.

Open Access This article is licensed under a Creative Commons Attribution 4.0 International License, which permits use, sharing, adaptation, distribution and reproduction in any medium or format, as long as you give appropriate credit to the original author(s) and the source, provide a link to the Creative Commons license, and indicate if changes were made. The images or other third party material in this article are included in the article's Creative Commons license, unless indicated otherwise in a credit line to the material. If material is not included in the article's Creative Commons license and your intended use is not permitted by statutory regulation or exceeds the permitted use, you will need to obtain permission directly from the copyright holder. To view a copy of this license, visit http://creativecommons.org/licenses/by/4.0/.

\section{References}

1. World Health Organization. Noncommunicable diseases. https://www.who.int/news-room/fact-sheets/detail/ noncommunicable-diseases. Accessed 9 August 2020.

2. Roser M, Ritchie H "Burden of disease". https://ourworldindata. org/burden-of-disease. Accessed 4 August 2020.

3. World Health Organization. Cardiovascular diseases (CVDs). https://www.who.int/news-room/fact-sheets/detail/cardiovascula r-diseases-(cvds). Accessed 11 August 2020.

4. World Health Organization. Hypertension. https://www.who.int/new s-room/fact-sheets/detail/hypertension. Accessed 11 August 2020.

5. Chopra H, Ram CVS. Recent guidelines for hypertension: a clarion call for blood pressure control in India. Circ Res. 2019;124:984-6.

6. Nguyen B, Bauman A, Ding D. Association between lifestyle risk factors and incident hypertension among middle-aged and older Australians. Prev Med. 2019;118:73-80.

7. Mills KT, Bundy JD, Kelly TN, Reed JE, Kearney PM, Reynolds $\mathrm{K}$, et al. Global disparities of hypertension prevalence and control: a systematic analysis of population-based studies from 90 countries. Circulation. 2016;134:441-50.

8. Baffour-Awuah B, Dieberg G, Pearson MJ, Smart NA. Blood pressure control in older adults with hypertension: a systematic review with meta-analysis and meta-regression. IJCHy. 2020;6:100040.

9. Smart NA, Gow J, Bleile B, Van der Touw T, Pearson MJ. An evidence-based analysis of managing hypertension with isometric resistance exercise-are the guidelines current? Hypertens Res. 2020;43:249-54.

10. Aucott L, Poobalan A, Smith WCS, Avenell A, Jung R, Broom J. Effects of weight loss in overweight/obese individuals and longterm hypertension outcomes: a systematic review. Hypertension. 2005;45:1035-41.

11. Selçuk KT, Çevik C, Mercan Y, Koca H. Hypertensive patients' adherence to pharmacological and non-pharmacological treatment methods, in Turkey. Int J Community Med Public Health. 2017;4:2648-57.

12. Stevens VJ, Obarzanek E, Cook NR, Lee I-M, Appel LJ, West DS, et al. Long-term weight loss and changes in blood pressure: results of the trials of hypertension prevention, phase II. Ann Intern Med. 2001;134:1-11.

13. Brook RD, Jackson EA, Giorgini P, McGowan CL. When and how to recommend 'alternative approaches' in the management of high blood pressure. Am J Med. 2015;128:567-70.

14. Schroeder EC, Franke WD, Sharp RL, Lee DC. Comparative effectiveness of aerobic, resistance, and combined training on cardiovascular disease risk factors: a randomized controlled trial. PLoS ONE. 2019; 14:e0210292.
15. Sardeli AV, Griffth GJ, dos Santos MVMA, Ito MSR, ChaconMikahil MPT. The effects of exercise training on hypertensive older adults: an umbrella meta-analysis. Hypertens Res. 2021;44:1434-43.

16. Whelton PK, Carey RM, Aronow WS, Casey DE, Collins KJ, Himmelfarb CD, et al. 2017 ACC/AHA/AAPA/ABC/ACPM/ AGS/APhA/ASH/ASPC/NMA/PCNA guideline for the prevention, detection, evaluation, and management of high blood pressure in adults. A report of the American College of Cardiology/American Heart Association task force on clinical practice guidelines. J Am Coll Cardiol. 2018;71:e127-248.

17. Hua Q, Fan L, Li J, Joint Committee for Guideline R. 2019 Chinese guideline for the management of hypertension in the elderly. J Geriatr Cardiol. 2019;16:67-99.

18. Kim K-I, Ihm S-H, Kim G-H, Kim HC, Kim JH, Lee H-Y, et al. 2018 Korean society of hypertension guidelines for the management of hypertension: part III-hypertension in special situations. Clin Hypertens. 2019;25:19.

19. Nerenberg KA, Zarnke KB, Leung AA, Dasgupta K, Butalia S, McBrien K, et al. Hypertension Canada's 2018 Guidelines for diagnosis, risk assessment, prevention, and treatment of hypertension in adults and children. Can J Cardiol. 2018; 34:506-25.

20. Précoma DB, Oliveira GMMD, Simão AF, Dutra OP, Coelho $\mathrm{OR}$, Izar MCDO, et al. Updated cardiovascular prevention guideline of the Brazilian Society of Cardiology - 2019. Arquivos Brasileiros de Cardiologia. 2019;113:787-891.

21. Shah SN, Munjal YP, Kamath SA, Wander GS, Mehta N, Mukherjee S, et al. Indian guidelines on hypertension-IV (2019). J Hum Hypertens. 2020;34:745-58.

22. Stamatakis E, Straker L, Hamer M, Gebel K. The 2018 physical activity guidelines for Americans: What's new? Implications for clinicians and the public. J Orthop Sports Phys Ther. 2019;49:487-90.

23. Umemura S, Arima H, Arima S, Asayama K, Dohi Y, Hirooka $\mathrm{Y}$, et al. The Japanese Society of Hypertension guidelines for the management of hypertension (JSH 2019). Hypertens Res. 2019;42:1235-481.

24. Unger T, Borghi C, Charchar F, Khan NA, Poulter NR, Prabhakaran D, et al. 2020 International Society of Hypertension global hypertension practice guidelines. J Hypertens. 2020;38:982-1004.

25. Williams B, Mancia G, Spiering W, Agabiti Rosei E, Azizi M, Burnier M, et al. 2018 ESC/ESH Guidelines for the management of arterial hypertension. The Task Force for the management of arterial hypertension of the European Society of Cardiology (ESC) and the European Society of Hypertension (ESH). Eur Heart J. 2018;39:3021-104.

26. Czarnecka D, Jankowski P, Kopeć G, Pająk A, Podolec J, Zdrojewski T, et al. Polish forum for prevention guidelines on hypertension: update 2017. Kardiologia Pol (Pol Heart J). 2017;75:282-5.

27. Cuspidi C, Tadic M, Grassi G, Mancia G. Treatment of hypertension: The ESH/ESC guidelines recommendations. Pharm Res. 2018;128:315-21.

28. Antza C, Doundoulakis I, Stabouli S, Kotsis V. Comparison among recommendations for the management of arterial hypertension issued by last US, Canadian, British and European Guidelines. High Blood Press Cardiovasc Prev. 2018;25:9-16.

29. Schutzer KA, Graves BS. Barriers and motivations to exercise in older adults. Prev Med. 2004;39:1056-61.

30. Trost SG, Owen N, Bauman AE, Sallis JF, Brown W. Correlates of adults' participation in physical activity: review and update. Med Sci Sports Exerc. 2002;34:1996-2001.

31. Baddeley-White DS, McGowan CL, Howden R, Gordon BD, Kyberd P, Swaine IL. Blood pressure lowering effects of a novel isometric exercise device following a 4-week isometric handgrip intervention. Open Access J Sports Med. 2019;10:89-98. 
32. Badrov M, Bartol C, DiBartolomeo M, Millar P, McNevin N, McGowan C. Effects of isometric handgrip training dose on resting blood pressure and resistance vessel endothelial function in normotensive women. Eur J Appl Physiol. 2013;113:2091-100.

33. Badrov MB, Freeman SR, Zokvic MA, Millar PJ, McGowan CL. Isometric exercise training lowers resting blood pressure and improves local brachial artery flow-mediated dilation equally in men and women. Eur J Appl Physiol. 2016;116:1289-96.

34. Chen W, Ni J, Qiao Z, Wu Y, Lu L, Zheng J, et al. Comparison of the clinical outcomes of two physiological ischemic training methods in patients with coronary heart disease. Open Med (Wars). 2019;14:224-33

35. Herrod PJJ, Blackwell JEM, Moss BF, Gates A, Atherton PJ, Lund JN, et al. The efficacy of 'static' training interventions for improving indices of cardiorespiratory fitness in premenopausal females. Eur J Appl Physiol. 2019;119:645-52.

36. Hess NCL, Carlson DJ, Inder JD, Jesulola E, McFarlane JR, Smart NA. Clinically meaningful blood pressure reductions with low intensity isometric handgrip exercise. A randomized trial. Physiol Res. 2016;65:461-8.

37. Gordon BDH, Whitmire S, Zacherle EW, Doyle S, Gulati S, Leamy LJ, et al. "Get a grip on hypertension": exploring the use of isometric handgrip training in cardiopulmonary rehabilitation patients. J Cardiopulm Rehabil Prev. 2019;39:E31-4.

38. Correia MA, Oliveira PL, Farah BQ, Vianna LC, Wolosker N, Puech-Leao $\mathrm{P}$, et al. Effects of isometric handgrip training in patients with peripheral artery disease: a randomized controlled trial. J Am Heart Assoc. 2020;9:e013596.

39. Hornig B, Maier V, Drexler H. Physical training improves endothelial function in patients with chronic heart failure. Circulation. 1996;93:210-4.

40. Katz SD, Yuen J, Bijou R, Lejemtel TH. Training improves endothelium-dependent vasodilation in resistance vessels of patients with heart failure. J Appl Physiol. 1997;82:1488-92.

41. Carlson DJ, Dieberg G, Hess NC, Millar PJ, Smart NA. Isometric exercise training for blood pressure management: a systematic review and meta-analysis. Mayo Clin Proc. 2014;89:327-34.

42. Inder JD, Carlson DJ, Dieberg G, McFarlane JR, Hess NC, Smart NA. Isometric exercise training for blood pressure management: a systematic review and meta-analysis to optimize benefit. Hypertens Res. 2016;39:88-94.

43. Lopez-Valenciano A, Ruiz-Perez I, Ayala F, Sanchez-Meca J, Vera-Garcia FJ. Updated systematic review and meta-analysis on the role of isometric resistance training for resting blood pressure management in adults. J Hypertens. 2019;37:1320.

44. Smart NA, Way D, Carlson D, Millar P, McGowan C, Swaine I, et al. Effects of isometric resistance training on resting blood pressure: individual participant data meta-analysis. J Hypertens. 2019;37:1927-38.

45. Lopes S, Afreixo V, Teixeira M, Garcia C, Leitão C, Gouveia M, et al. Exercise training reduces arterial stiffness in adults with hypertension: a systematic review and meta-analysis. J Hypertens. 2021;39:214-22.

46. Oliver-Martínez PA, Ramos-Campo DJ, Martínez-Aranda LM, Martínez-Rodríguez A, Rubio-Arias JÁ. Chronic effects and optimal dosage of strength training on SBP and DBP: a systematic review with meta-analysis. J Hypertens. 2020;38:1909-18.

47. Polito MD, Dias JR Jr, Papst RR. Resistance training to reduce resting blood pressure and increase muscle strength in users and non-users of anti-hypertensive medication: a meta-analysis. Clin Exp Hypertens. 2021;43:474-85.

48. Maior AS, Katayama PL, Mota GR, Lauria AA, Neto OB, Freitas DGS, et al. Acute responses of rate pressure product in sets of resistance exercise. Med Sport. 2014;18:36-41.

49. Pollock ML, Franklin BA, Bazzarre T, Balady GJ, Chaitman BL, Fleg JL, et al. Resistance exercise in individuals with and without cardiovascular disease: benefits, rationale, safety, and prescription an advisory from the committee on exercise, rehabilitation, and prevention, council on clinical cardiology, American Heart Association. Circulation. 2000;101:828-33.

50. Hui SC, Jackson AS, Wier LT. Development of normative values for resting and exercise rate pressure product. Med Sci Sports Exerc. 2000;32:1520-7.

51. Lee H-Y, Shin J, Kim G-H, Park S, Ihm S-H, Kim HC, et al. 2018 Korean Society of Hypertension Guidelines for the management of hypertension: part II-diagnosis and treatment of hypertension. Clin Hypertens. 2019;25:20.

52. Sharman JE, Smart NA, Coombes JS, Stowasser M. Exercise and sport science Australia Position Stand update on exercise and hypertension. J Hum Hypertens. 2019;33:837-43.

53. Hansford HJ, Parmenter BJ, McLeod KA, Wewege MA, Smart NA, Schutte AE, et al. The effectiveness and safety of isometric resistance training for adults with high blood pressure: a systematic review and meta-analysis. Hypertens Res. 2021;44:1373-84.

54. Joint Committee for Guideline Revision. 2018 Chinese guidelines for prevention and treatment of hypertension - a report of the Revision Committee of Chinese guidelines for prevention and treatment of hypertension. J Geriatr Cardiol. 2019;16:182-241.

55. Chiang CE, Wang TD, Ueng KC, Lin TH, Yeh HI, Chen CY, et al. 2015 Guidelines of the Taiwan Society of cardiology and the Taiwan hypertension society for the management of hypertension. J Chin Med Assoc. 2015;78:1-47.

56. Hansen D, Niebauer J, Cornelissen V, Barna O, Neunhäuserer D, Stettler C, et al. Exercise prescription in patients with different combinations of cardiovascular disease risk factors: a consensus statement from the EXPERT working group. Sports Med. 2018;48:1781-97.

57. Harbour R, Miller J. A new system for grading recommendations in evidence based guidelines. BMJ. 2001;323:334-6.

58. Pescatello LS, Buchner DM, Jakicic JM, Powell KE, Kraus WE, Bloodgood B, et al. Physical activity to prevent and treat hypertension: a systematic review. Med Sci Sports Exerc. 2019;51:1314-23.

59. Kelley GA, Kelley KS, Stauffer BL. Isometric exercise and interindividual response differences on resting systolic and diastolic blood pressure in adults: a meta-analysis of randomized controlled trials. Blood Pressure. 2021:1-12. https://doi.org/10. 1080/08037051.2021.1940837.

60. Loaiza-Betancur AF, Perez Bedoya E, Montoya Davila J, ChulviMedrano I. Effect of isometric resistance training on blood pressure values in a group of normotensive participants: a systematic review and meta-analysis. Sport Health. 2020;12:256-62.

61. Fu J, Liu Y, Zhang L, Zhou L, Li D, Quan H, et al. Nonpharmacologic interventions for reducing blood pressure in adults with prehypertension to established hypertension. J Am Heart Assoc. 2020;9:e016804.

62. Keeney S, Hasson F, McKenna H. The Delphi technique. In: The Delphi Technique in Nursing and Health Research. 2010:1-17. https://doi.org/10.1002/9781444392029.ch1.

63. Jones J, Hunter D. Consensus methods for medical and health services research. BMJ. 1995;311:376-80.

64. Keeney S, Hasson F, McKenna H. Conducting the research using the Delphi technique. In: The Delphi Technique in Nursing and Health Research. 2010:69-83. https://doi.org/10.1002/9781444392029.ch5.

65. Kelley GA, Kelley KS. Isometric handgrip exercise and resting blood pressure: a meta-analysis of randomized controlled trials. J Hypertens. 2010;28:411-8.

66. Souza LHR, Soares BR, Melo GR, Olher RR, Silva WM, Euzébio TA, et al. Effects of isometric exercise on blood pressure in normotensive and hypertensive older adults: a systematic review. J Exerc Physiol Online. 2019;22:92-108. 
67. Farah BQ, Germano-Soares AH, Rodrigues SLC, Santos CX, Barbosa SS, Vianna LC, et al. Acute and chronic effects of isometric handgrip exercise on cardiovascular variables in hypertensive patients: a systematic review. Sports. 2017;5:55.

68. Owen A, Wiles J, Swaine I. Effect of isometric exercise on resting blood pressure: a meta analysis. J Hum Hypertens. 2010;24:796-800.

69. Hasson F, Keeney S, McKenna H. Research guidelines for the Delphi survey technique. J Adv Nurs. 2000;32:1008-15.

70. Keeney S, Hasson F, McKenna H. Debates, criticisms and limitations of the Delphi. In: The Delphi Technique in Nursing and Health Research. 2010:18-31. https://doi.org/10.1002/ 9781444392029.ch2.

71. Qualtrics [computer program]. Version January 2021. Qualtrics: Provo, Utah, USA; 2021.

72. Haynes E, Palermo C, Reidlinger DP. Modified Policy-Delphi study for exploring obesity prevention priorities. BMJ Open. 2016;6:e011788.

73. Knighting K, O'Brien MR, Roe B, Gandy R, Lloyd-Williams M, Nolan M, et al. Gaining consensus on family carer needs when caring for someone dying at home to develop the Carers' Alert Thermometer (CAT): a modified Delphi study. J Adv Nurs. 2016;72:227-39.

74. Tonkin-Crine S, Pruthi R, Taylor DM, Leydon GM, Calestani M, Oniscu GC, et al. Assessing consensus between UK renal clinicians on listing for kidney transplantation: a modified Delphi study. Transplant Direct. 2018;4:e343.

75. Eubank BH, Mohtadi NG, Lafave MR, Wiley JP, Bois AJ, Boorman RS, et al. Using the modified Delphi method to establish clinical consensus for the diagnosis and treatment of patients with rotator cuff pathology. BMC Med Res Methodol. 2016;16:56.

76. Kearney A, Williamson P, Young B, Bagley H, Gamble C, Denegri S, et al. Priorities for methodological research on patient and public involvement in clinical trials: a modified Delphi process. Health Expect: Int J Pub Participation Health Care Health Policy. 2017;20:1401-10.

77. Woodcock T, Adeleke Y, Goeschel C, Pronovost P, DixonWoods M. A modified Delphi study to identify the features of high quality measurement plans for healthcare improvement projects. BMC Med Res Methodol. 2020;20:8.

78. Price J, Rushton A, Tyros V, Heneghan NR. Expert consensus on the important chronic non-specific neck pain motor control and segmental exercise and dosage variables: an international e-Delphi study. PLoS ONE. 2021;16:e0253523.

79. Walker MA, Selfe MJ. The Delphi method: a useful tool for the allied health researcher. BJTR. 1996;3:677-81.

80. von der Gracht HA. Consensus measurement in Delphi studies: aeview and implications for future quality assurance. Technol Forecast Soc Change. 2012;79:1525-36.

81. IBM SPSS Statistics for Windows [computer program]. Version 25.0 IBM Corp: Armonk, NY; 2017.

82. Wiles JD, Taylor K, Coleman D, Sharma R, O'Driscoll JM. The safety of isometric exercise: Rethinking the exercise prescription paradigm for those with stage 1 hypertension. Medicine. 2018;97:e0105.

83. Carlson DJ, McFarlane JR, Dieberg G, Smart NA, Nobuo H. Rate pressure product responses during an acute session of isometric resistance training: a randomized trial. J Hypertens Cardiol. 2017;2:1-11.

84. Carlson DJ, Inder J, Palanisamy SKA, McFarlane JR, Dieberg G, Smart NA. The efficacy of isometric resistance training utilizing handgrip exercise for blood pressure management: a randomized trial. Medicine. 2016;95:e5791.

85. Wiles JD, Goldring N, Coleman D. Home-based isometric exercise training induced reductions resting blood pressure. Eur $\mathbf{J}$ Appl Physiol. 2017;117:83-93.
86. Punia S, Kulandaivelan S. Home-based isometric handgrip training on RBP in hypertensive adults-Partial preliminary findings from RCT. Physiother Res Int. 2019; e1806. (e-pub ahead of print 17 August 2019; https://doi.org/10.1002/pri.1806).

87. Kim D, Ha J-W. Hypertensive response to exercise: mechanisms and clinical implication. Clin Hypertens. 2016;22:17.

88. Parati G, Zhang Y. Assessing blood pressure response to exercise: methodological issues and clinical relevance. J Hypertens. 2015;33:1364-7.

89. Rossi V, Niederseer D. Exercise hypertension - a review. SEMSjournal 2019. (e-pub ahead of print 1 November 2019; https:// doi.org/10.34045/SSEM/2019/14).

90. Shim CY, Ha J-W, Park S, Choi E-Y, Choi D, Rim S-J, et al. Exaggerated blood pressure response to exercise is associated with augmented rise of angiotensin II during exercise. J Am Coll Cardiol. 2008;52:287-92.

91. O'Driscoll JM, Boucher C, Vilda M, Taylor KA, Wiles JD. Continuous cardiac autonomic and haemodynamic responses to isometric exercise in females. Eur J Appl Physiol. 2021;121:319-29.

92. Rankinen T, Bouchard C. Genetics and blood pressure response to exercise, and its interactions with adiposity. Prev Cardiol. 2002;5:138-44.

93. de Lima SG, de Albuquerque MDFPM, de Oliveira JRM, Ayres CFJ, da Cunha JEG, de Oliveira DF, et al. Exaggerated blood pressure response during exercise treadmill testing: functional and hemodynamic features, and risk factors. Hypertens Res. 2012;35:733-8.

94. Kunchakarra S, Martin B, Maharaj V, Brailovsky Y, Sanagala T. Abstract 16553: predictors of hypertensive response during exercise stress echocardiography. Circulation. 2017;136:A16553.

95. de Oliveira EM, Alves GB, Barauna VG. Sistema reninaangiotensina: interação gene-exercício. Rev Bras Hipertens. 2003;10:125-9.

96. Shim CY, Hong G-R, Park S, Yang W-I, Choi D, Chung N, et al. Impact of central haemodynamics on left ventricular function in individuals with an exaggerated blood pressure response to exercise. J Hypertens. 2015;33:612-20.

97. Stewart KJ, Sung J, Silber HA, Fleg JL, Kelemen MD, Turner KL, et al. Exaggerated exercise blood pressure is related to impaired endothelial vasodilator function. Am J Hypertens. 2004;17:314-20.

98. Campbell R, Fisher JP, Sharman JE, McDonnell BJ, Frenneaux MP. Contribution of nitric oxide to the blood pressure and arterial responses to exercise in humans. J Hum Hypertens. 2011;25:262-70.

99. American College of Sports Medicine, Riebe D, Ehrman JK, Liguori G, Magal M. ACSM's guidelines for exercise testing and prescription. (e-pub ahead of print Tenth. Published Tenth.). Tenth edn. Wolters Kluwer: Philadelphia, 2018.

100. Pinkstaff S, Peberdy MA, Kontos MC, Finucane S, Arena R. Quantifying exertion level during exercise stress testing using percentage of age-predicted maximal heart rate, rate pressure product, and perceived exertion. Mayo Clin Proc. 2010;85:1095-1100.

101. Seidel M, Pagonas N, Seibert FS, Bauer F, Rohn B, Vlatsas S, et al. The differential impact of aerobic and isometric handgrip exercise on blood pressure variability and central aortic blood pressure. J Hypertens. 2021;39:1269-73.

102. Taylor KA, Wiles JD, Coleman DD, Sharma R, O’Driscoll JM. Continuous cardiac autonomic and hemodynamic responses to isometric exercise. Med Sci Sports Exerc. 2017;49:1511-9.

103. Taylor KA, Wiles JD, Coleman DA, Leeson P, Sharma R, O'Driscoll JM. Neurohumoral and ambulatory haemodynamic adaptations following isometric exercise training in unmedicated hypertensive patients. J Hypertens. 2019;37:827-36.

104. Lea JWD, O'Driscoll JM, Coleman DA, Wiles JD. Validity and reliability of RPE as a measure of intensity during isometric wall squat exercise. J Clin Transl Res. 2021;7:248-56. 